\title{
Identification of Phospho-Tyrosine Targets as a Strategy for the Treatment of Esophageal Adenocarcinoma Cells
}

\author{
John Lee \\ Rongbing Chen (D) \\ $T$ Mohanakumar \\ Ross Bremner \\ Sumeet Mittal \\ Timothy P Fleming
}

Norton Thoracic Institute, St. Joseph Hospital, Phoenix, AZ, USA
Correspondence: Timothy P Fleming St. Joseph's Hospital and Medical Center, Norton Thoracic Institute, 124

W. Thomas Road, Suite I05, Phoenix, AZ 85013, USA

Tel +| 3|4-960-233|

Email Timothy.Fleming@commonspirit.

org
Introduction: Esophageal cancer (EC) is an aggressive cancer type that is increasing at a high rate in the US and worldwide. Extensive sequencing of EC specimens has shown that there are no consistent driver mutations that can impact treatment strategies. The goal of this study was to identify activated tyrosine kinase receptors (TKRs) in EC samples as potential targets in the treatment of EC.

Methods: Activated tyrosine kinase receptors were detected using a dot-blot array for human TK receptors. Human esophageal cancer cell lines were transplanted into immunocompromised mice, and tumor xenografts were subjected to tyrosine kinase inhibitors based on the dot-blot array data.

Results: Using the OE33 esophageal cancer cell line, we identified activated EGF receptor (EGFR), as well as ErbB2 and ErbB3. Treatment of this cell line with erlotinib, a specific inhibitor of EGFR, did not impact the growth of this tumor cell line. Treating the OE33 cell line with afatinib, a pan-EGFR family inhibitor resulted in the growth inhibition of OE33, indicating that the ErbB2 and ErbB3 receptors were contributing to tumor cell proliferation. Afatinib treatment of mice growing OE33 tumors inhibited growth of the OE33 tumor cells. Discussion: Activated tyrosine kinase receptors were readily detected in both cancer cell lines and human esophageal cancer samples. By identifying the activated receptors and then using the appropriate tyrosine kinase inhibitors, we can block tumor growth in vitro and in animal xenografts. We propose that identifying and targeting activated TKRs can be used as a personalized EC tumor treatment strategy.

Keywords: tyrosine phosphorylation, tyrosine kinase receptors, esophageal cancer, treatment, kinase inhibitors

\section{Introduction}

Esophageal cancer (EC) is one of the least studied and deadliest cancers based on its aggressive nature and poor survival rate. ${ }^{1,2}$ It ranks sixth among all cancers in mortality world-wide. Risk factors for developing EC include smoking, red meat consumption, acid reflux, and obesity. Esophageal cancer is diagnosed in about 18,000 Americans every year with a mortality rate of more than $80 \%$ within five years, and a median overall survival of just 13 months. ${ }^{3,4}$ Treatment of esophageal cancer is generally the use of taxane and platinum-based chemotherapy regimens. ${ }^{5}$

Studies doing comprehensive sequencing and bioinformatics analysis of large pools of EC patients have not been productive in identifying common cancerdriving mutations. ${ }^{6,7}$ Highly penetrant oncogenes are rarely found in EC, 
suggesting that EC is a result of multiple genetic changes. A recent report from the Fitzgerald lab evaluated the sequence of 551 EC samples. ${ }^{8}$ This work provided a detailed collection of mutations and copy number alterations. However, there were no consistent driver mutations identified even with this large population of EC samples.

To identify personalized and druggable targets in esophageal cancer patients, we postulated an alternate investigative strategy based on the detection and analysis of phosphoproteins. ${ }^{9-11}$ Proteins are the effector molecules in tumor cells and their functional status is modulated through posttranslational modifications, of which phosphorylation is the most common change in cellular proliferation. Tyrosine kinase activation is impactful in many tumor types, and in fact, tyrosine kinase inhibitors are one of the more useful therapeutics currently in cancer treatment. $^{12-14}$

To identify therapeutic targets that may be involved in an individual's EC, our laboratory evaluated the tyrosinephosphorylation status of both esophageal cancer cell lines and biopsy material from EC. We found that phosphotyrosine detection was highly reproducible in both the cell lines and biopsies. This strategy allowed us to identify activated growth factor receptors in both esophageal tumor cell lines, and biopsy samples will allow us to identify FDA-approved tyrosine kinase inhibitors (TKIs) that specifically target those receptors.

\section{Materials and Methods \\ Cell Culture and Reagents}

The human esophageal adenocarcinoma cell lines OE33 and FLO-1 (MilliporeSigma, St. Louis, MO) were cultured using RPMI 1640 containing 10\% fetal bovine serum with $2 \mathrm{mM}$ glutamine at $37^{\circ} \mathrm{C}$, in a humid environment with $5 \%$ $\mathrm{CO} 2$. Cells were checked for mycoplasma contamination using PCR mycoplasma detection kits from Applied Biological Materials. Afatinib and erlotinib were obtained from Selleck Chemicals (Houston, Tx), and we used mycoplasma-free OE33 for all our analysis.

\section{Characterization of Receptor Tyrosine Kinase Activity}

For analysis of RTK activity in cell lines and biopsy samples, the Human Phospho-RTK array kit (ARY001B; R\&D Systems, Minneapolis, MN) was used to profile the RTK activity of the samples. Concisely, proteins were extracted using the lysis buffer, diluted, and incubated overnight over the array, then incubated with HRP-detection antibody, and visualized with the chemi-luminescent reagent.

The use of human tissues for this study has been approved by the St. Joseph Hospital and Medical Center, Phoenix, AZ IRB Board (IRB PHXB-12FHL078 Dignity Health Research Study). This study was performed in accordance with the Declaration of Helsinki. All samples collected had written and informed patient consent. For human biopsy samples, the sample was first homogenized with razor blades in lysis buffer supplemented with protease inhibitor cocktail and phosphatase inhibitor cocktail 2 (MilliporeSigma, St. Louis, MO). Then, the manufacturer's instructions were followed as above.

\section{Immunoprecipitation of Phosphor-Tyrosine Proteins from Human Esophagus Cancer Cells}

To isolate the phospho-tyrosine proteins, we followed the protocol recommended by the manufacturer Abcam immunoprecipitation kit (ab206996; Cambridge, MA). In short, cells were lysed with in lysis buffer, centrifuged, and the resulting supernatant transferred to a tube containing PY20 anti-phospho-tyrosine mouse antibody (BD Biosciences; San Jose, CA) for overnight incubation, then allowed to form a complex with the capturing beads. The complex was eluted with SDS-PAGE loading buffer for Western blot analysis.

\section{Western Blot Analysis}

For Western blot analysis, samples were rinsed with phosphate-buffered saline, lysed in RIPA buffer supplemented with protease inhibitor cocktail and phosphatase inhibitor cocktail 2 (MilliporeSigma, St. Louis, MO), and centrifuged for 5 minutes at $14,000 \mathrm{rpm}^{15}$ The resulting protein supernatants were mixed with reducing SDS sample buffer and subjected to SDS-PAGE. After transferring onto PVDF, the proteins were blocked using 3\% bovine serum albumin (Fraction V; Research Products International, Mt. Prospect, IL) in phosphate-buffered saline with $0.1 \%$ Tween 20 , then incubated overnight with PY20 anti-phospho-tyrosine mouse antibody (BD Biosciences; San Jose, CA), followed up with anti-mouse antibody and developed with Pico chemiluminescent substrate from ThermoScientific (Rockford, IL).

\section{Mouse Xenograft}

All animal experiment protocols were reviewed and approved by the St. Joseph Hospital and Medical Center Institutional Review Board (IACUC \#522 protocol). Animal 
treatment followed all institutional guidelines for the care and use of animals. All animal procedures were in accordance with the Animal Welfare Act (7 U.S.C. 2131 et seq.).

Six- to eight-week-old SCID mice ( 12 females, 8 males, with average weight $26 \mathrm{~g}$ ) were acquired from Charles River Laboratories (Wilmington, MA), and maintained in the animal facility. The mice were randomly divided up into four groups: experimental mice received $\sim 1 \times 10^{6} \mathrm{OE} 33$ cells and control mice received media with no cells. One week posttransplant, these mice were then treated with Afatinib (Selleck Chemicals Llc, Houston, TX) or with vehicle only. To induce xenograft growth, the OE33 cells were suspended in $100 \mu \mathrm{Ls}$ of Corning Matrigel Matrix on ice, and cells were injected subcutaneously into the mouse under anesthesia. The mice showed no signs of toxicity, such as loss of body weight over the course of treatment. Afatinib solution was prepared according to the manufacturer's recommendation (water with 30\% PEG300 and 5\% DMSO), and was given to mice by gavage at $25 \mathrm{mg} / \mathrm{kg}$, daily. Cells formed solid masses over three weeks. Tumor volume was determined by external caliber and using the modified ellipsoid formula: $1 / 2$ (Length $\times$ Width $\left.^{2}\right)^{16,17}$ Experimental mice were monitored daily. In the case where a tumor developed ulcerations or movement of the host was affected by the tumor, the animal was euthanized.

\section{Statistical Analysis}

Statistical analysis was performed using GraphPad Prism software. Two-sided, nonparametric Mann-Whitney test was used to compare the data between two groups. $\mathrm{P}$ values less than 0.05 were considered statistically significant.

\section{Results}

Detection of Tyrosine Phosphorylation of Growth Factor Receptors in Esophageal Cancer Cell Lines

To identify targets for the treatment of esophageal cancer, we performed an anti-phospho-tyrosine dot blot on two esophageal cancer cell lines, OE33 and FLO-1. As seen in Figure 1, each cell line had a unique "signature" of activated growth factor receptors. In the OE33 cell line, the dominant pattern was observed in the EGFR family of receptors, including EGFR, ErbB2 (HER-2), and ErbB3, and strong tyrosine phosphorylation was also observed in the HGFR (MET) and MSRP. The tyrosine phosphorylation pattern in FLO-1 was confined to the IGF-1 receptor and the insulin receptor. The tyrosine-phosphorylated signatures were highly reproducible, indicating the reliability of this assay. Both positive and negative controls are part of the dot blot assay. In addition, we have analyzed a few tumor samples that do not yield any signal, indicating that non-specific signaling is not a common event.

In Figure 2 we show that tyrosine phosphorylated proteins could be detected using anti-phospho-tyrosine immunoprecipitation in the OE33 and FLO-1 cell lines. This protocol provides an additional assay strategy for detecting tyrosine phosphorylation that can be targeted for developing treatment strategies.

\section{Tyrosine Phosphorylation Detection in vivo}

To assess if the tyrosine phosphorylated signature observed in the OE33 cell line recapitulates in vivo, we grew the OE33 cell line in immunocompromised mice.
OE33

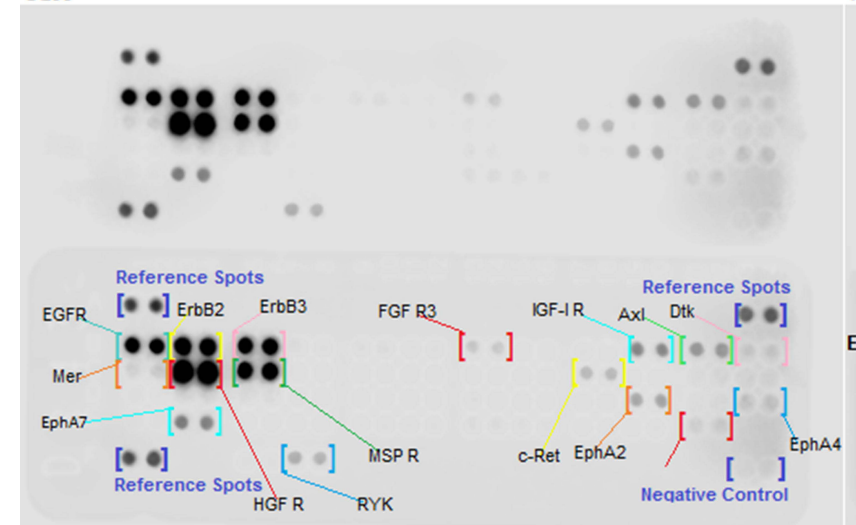

FLO-1


Figure I Detection of phospho-tyrosine growth factor receptors using a dot blot array. Phospho-tyrosine dot blot analyses of esophageal cancer cell lines OE33 and FLO-I. The lower portion of each panel is annotated showing what each positive spot represents. Note each blot has 3 internal reference spots that provide a comparator for comparing blots. The upper panel is the identical blot to the lower panel, without annotation. 


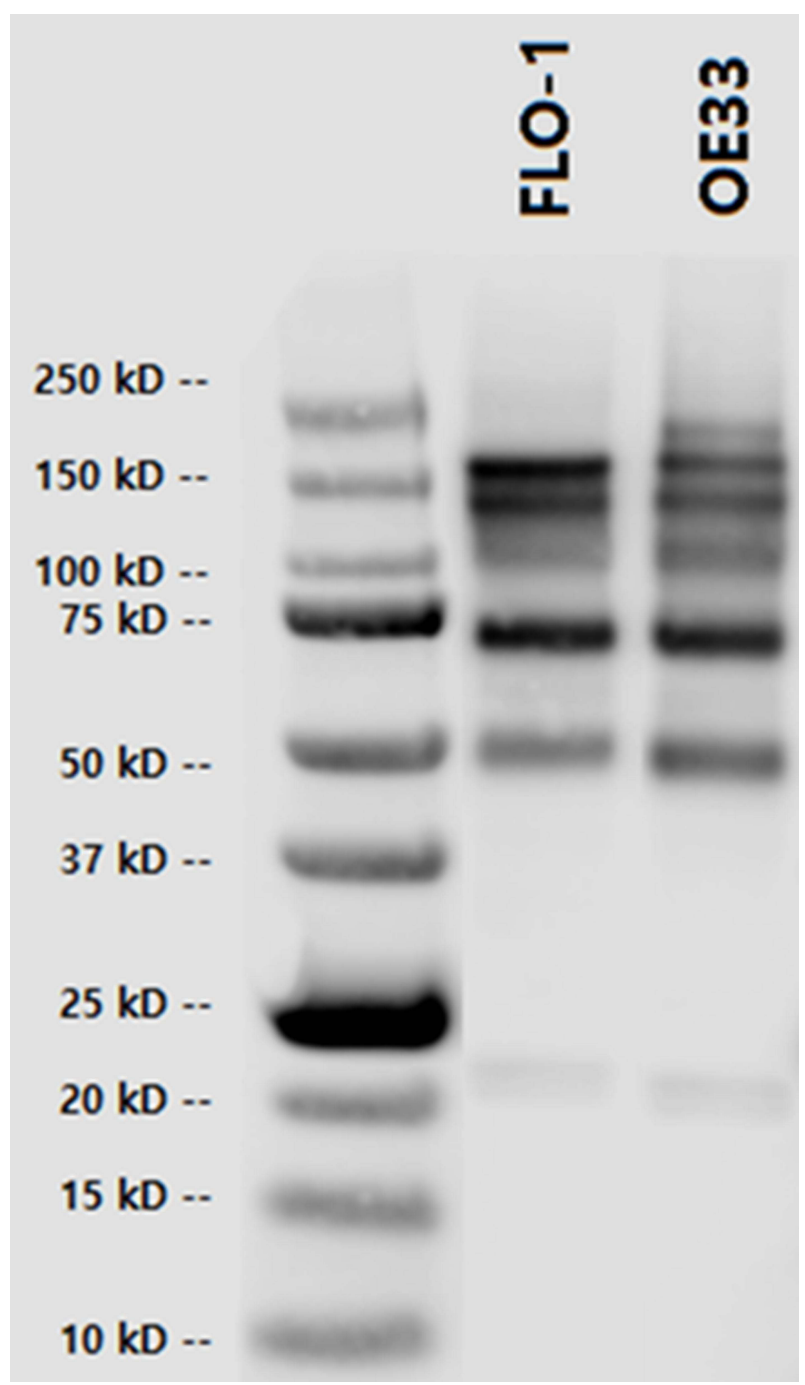

Figure 2 Phospho-tyrosine detection of OE-33 and FLO-I cell lines using immunoprecipitation. Cell lysates of esophageal cancer cell lines were immunoprecipitated with anti-phospho-tyrosine antibody PY20 and then blotted with the same antibody to maximize detection of tyrosine phosphorylated protein bands.

When the tumor grew to $0.5 \mathrm{~cm}$ in size, the tumor was harvested, processed, and analyzed by dot blot strategy. As seen in Figure 3, the dominant bands seen in vitro, and in vivo tumors were virtually identical. One exception was the MSP R signal. It was present in OE33 cells grown in vitro but was not detected in the in vivo tumor sample obtained from mice. This suggests that the MSP R signal is limited to OE33 grown in vitro.

\section{Targeting the Activated}

Tyrosine-Phosphorylated Growth Factor Receptors Inhibits Tumor Growth in vivo We treated the OE33 cell line in vitro with Erlotinib, a specific inhibitor of the EGFR. ${ }^{18}$ Phosphorylation of
EGFR was inhibited but did not result in growth arrest (data not shown). As Erlotinib is specific to the EGFR alone, it suggests that ErbB2 and ErbB3 may also be critical for the growth of OE33. When OE33 was treated with Afatinib, a pan EGFR inhibitor growth of OE33 in culture was completely inhibited (Figure 4). ${ }^{19,20}$ To test our hypothesis that tyrosine phosphorylated growth factor receptors could identify targets for therapy in esophageal cancer, we grew OE33 in immunocompromised mice with and without Afatinib. As seen in Figure 4, afatinib treatment significantly blocked the growth of OE33 in vivo.

\section{Human Esophageal Biopsy Material and Detection of Tyrosine-Phosphorylate Growth Factor Receptors}

To evaluate if human esophageal tumor tissue/biopsy material is amenable to phospho-tyrosine detection, we collected two independent esophageal biopsy samples and subjected them to dot blot analysis. As seen in Figure 5, clean signals were detected in both of the samples. Currently, we are attempting to obtain xenografts which will allow us to demonstrate that targeted treatment of the tyrosine-phosphorylated receptors observed can result in regression of the xenografted tumor samples.

\section{Discussion}

Our study demonstrates that the detection of activated tyrosine kinase receptors is technically feasible, easy, reproducible, and can identify activated receptors that are present in the tumor sample. Using an esophageal cancer cell line, OE33, and xenografted tumor cells, we identified the tyrosine phosphorylation pattern of the tumors which were similar to the cultured tumor cell line. We were able to target the EGFR family of tyrosine phosphorylations (EGFR, ErbB2, and ErbB3) with the pan-EGFR inhibitor, Afatinib. Afatinib treatment of the mice with the OE33 tumor resulted in a significant reduction of tumor growth. We propose that this strategy of detecting activated TKRs and treating with specific inhibitors is a model for the treatment of esophageal cancer patients. As there are no consistent targets amenable to therapy for esophageal cancer, our goal was to identify "personalized" targets for developing individualized treatment strategies.

One potential strategy is sequencing tumors, and to compare the tumor sequence to the sequence of that patient's normal tissue. Sequence analysis can help identify putative driver genes in a tumor, but limitations to 
A

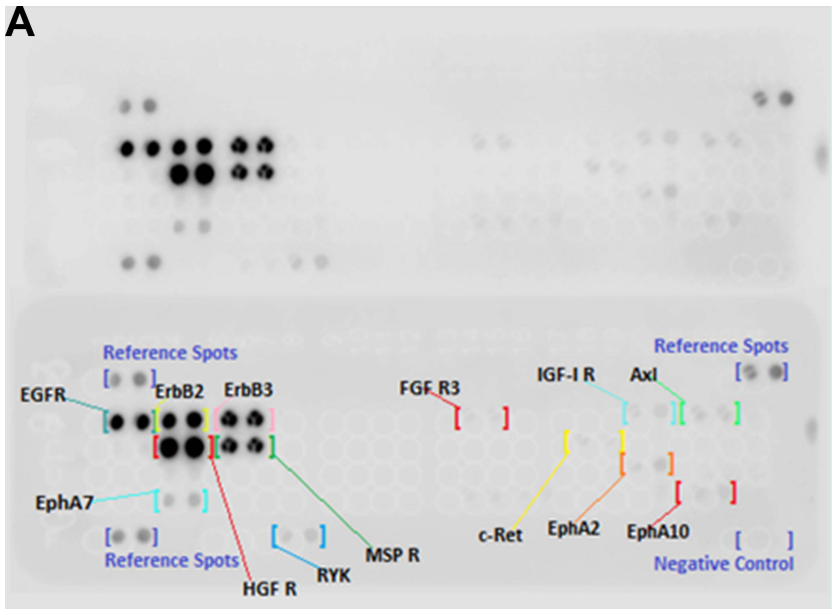

B

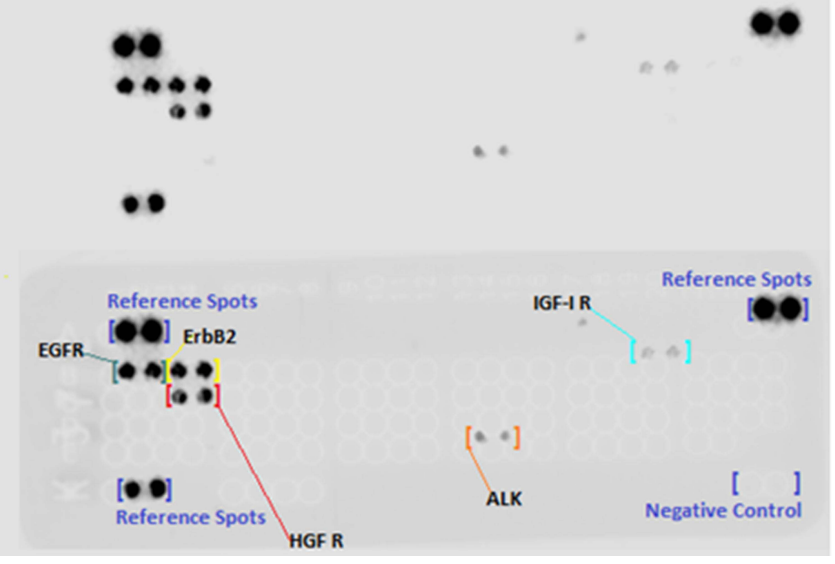

Figure 3 In vitro and in vivo phospho-tyrosine analysis of OE33 esophageal cell line. The left panel shows the in vitro tyrosine phosphorylation analysis of OE33 esophageal cell line and compared to OE33 (right panel) grown in vivo.

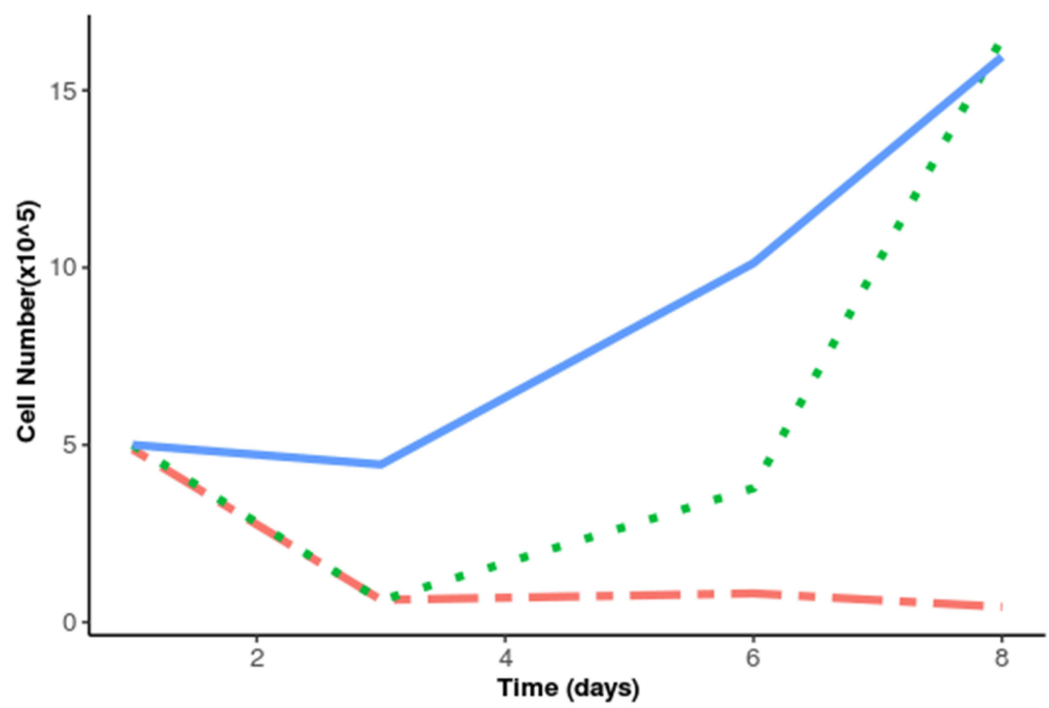

Figure 4 Growth curve of OE33 grown in the presence and absence of EGFR inhibitors. Cells growing in the presence of the EGFR specific inhibitor erlotinib (green dashes); cells growing with the pan-EGFR inhibitor Afatinib (orange dashes); and vehicle alone (blue dashes).

sequencing include the need for deep sequence analysis; sufficient tumor cells in the sample; and an appropriate level of analytic expertise to identify tumor driver mutations. One additional caveat is that epigenetic changes may be involved in tumor proliferation and these changes are not observed with ordinary sequencing.

There are several advantages of using a proteomicsbased assay for identifying targets for therapeutic intervention. These advantages include 1) relatively inexpensive, with rapid turn-around, with results available within 24 hrs; 2) identifies physiologic activation - not seen in sequence analysis; 3) RTK inhibitors are quite common and detection of activated RTKs can be readily targeted.
There are limitations to this study. For example, the detection of tyrosine phosphorylated proteins requires the use of fresh tissue, as freezing can impact the level of detectable tyrosine phosphorylation. Also, the dot blot assay does not provide coverage of all TK receptors. The addition of other TK receptors can be accomplished by the characterization and addition of other TK receptor antibodies.

Tyrosine kinases (TKs) are dysregulated in cancer cells in several ways. A common mechanism of TK activation in hematologic cancers is the fusion of a receptor TK with a partner protein, usually as a consequence of a chromosomal translocation. ${ }^{21,22}$ An example of this mechanism is BCR-ABL in chronic myeloid leukemia 


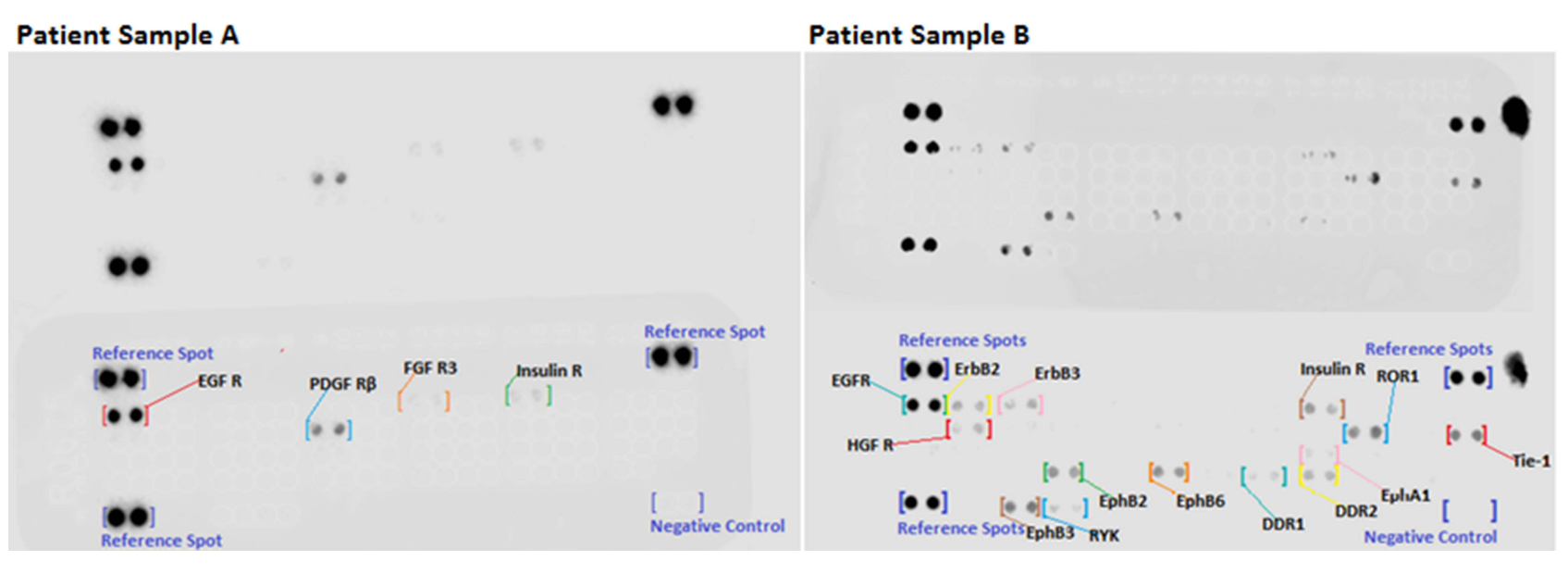

Figure 5 Phospho-tyrosine analysis of human esophageal cancer biopsy samples. Dot blot analysis of two independent biopsy samples demonstrating that specific activated growth factor receptors can be readily identified.

(CML). The BCR domain overcomes autoinhibition of the ABL catalytic domain and results in autophosphorylation and an aberrant growth signal. ${ }^{23}$ Gleevec (imatinib) was the first therapeutically successful tyrosine kinase inhibitor introduced for the treatment of CML. ${ }^{24}$ Gleevec targeted the Abl tyrosine kinase in CML patients.

A second important mechanism of TK dysregulation is a mutation that disrupts autoregulation of the kinase. Small deletions and point mutations in the kinase domain of epidermal growth factor receptor (EGFR) are responsible for the growth and proliferation of a subset of non-small-cell lung cancers. $^{25,26}$ Targeted inhibitors to EGFR, including erlotinib, ${ }^{27}$ gefitinib, ${ }^{28}$ and Afatinib $^{29}$ are all FDA-approved inhibitors to activated EGFR.

A third mechanism of TK dysregulation is increased or aberrant expression of a receptor TK, its ligand, or both. Examples include overexpression of TK ErbB2 (HER-2/ neu) in breast ${ }^{30,31}$ and other cancer types, and PDGFR and EGFR in glioblastoma. ${ }^{32,33}$ A fourth mechanism for increased TK activity in cancer cells results from a decrease in factors that limit TK activity, such as impaired tyrosine phosphatase activity $^{34,35}$ or decreased expression of TK inhibitor proteins. Aberrant TK activation can increase the survival, proliferation, increased angiogenesis, and metastatic ability of tumor cells.

By targeting activated tyrosine kinases in cancer, TK inhibitors significantly improved progression-free survival (PFS) and quality of life and sparing patients from toxic chemotherapy approaches. ${ }^{36,37}$ Phospho-Tyrosine analysis has shown to be an effective strategy to identify activated pathways in tumor cells. ${ }^{38,39}$ Personalized medicine and targeted therapy have shown a significant decrease in cancer deaths in the US. ${ }^{40}$

The long-term treatment of cancer patients with molecularly targeted TK inhibitors typically results in the resistance to the inhibitor. ${ }^{41,42}$ Resistance can be due to mutational changes to the targeted $\mathrm{TK}^{43}$ Additional mechanisms of chemoresistance are also involved, including alternative splicing, ${ }^{44}$ compensatory and redundant signaling pathways, ${ }^{45}$ and epigenetic changes. ${ }^{46}$ Understanding the mechanisms of TK resistance will allow for the inhibition of potential targets that result in TK resistance.

This manuscript demonstrates that activated tyrosine kinase receptors can readily be detected in esophageal cancer cell lines and human esophageal biopsy material. These activated tyrosine kinase receptors can be exploited as personalized targets for cancer therapy.

\section{Funding}

This work was funded by the St. Joseph Foundation.

\section{Disclosure}

None of the authors have a conflict of interest.

\section{References}

1. Zhang Y. Epidemiology of esophageal cancer. World J Gastroenterol. 2013;19(34):5598-5606. doi:10.3748/wjg.v19.i34.5598

2. Wong MCS, Hamilton W, Whiteman DC, et al. Global Incidence and mortality of oesophageal cancer and their correlation with socioeconomic indicators temporal patterns and trends in 41 countries. Sci Rep. 2018;8(1):4522. doi:10.1038/s41598-018-19819-8

3. Njei B, McCarty TR, Birk JW. Trends in esophageal cancer survival in United States adults from 1973 to 2009: a SEER database analysis. J Gastroenterol Hepatol. 2016;31(6):1141-1146. doi:10.1111/ jgh.13289 
4. Gaur P, Kim MP, Dunkin BJ. Esophageal cancer: recent advances in screening, targeted therapy, and management. J Carcinog. 2014;13 (1):11. doi:10.4103/1477-3163.143720

5. Abdo J, Agrawal DK, Mittal SK. Basis for molecular diagnostics and immunotherapy for esophageal cancer. Expert Rev Anticancer Ther. 2017;17(1):33-45. doi:10.1080/14737140.2017.1260449

6. Maag JLV, Fisher OM, Levert-Mignon A, et al. Novel aberrations uncovered in barrett's esophagus and esophageal adenocarcinoma using whole transcriptome sequencing. Mol Cancer Res. 2017;15 (11):1558-1569. doi:10.1158/1541-7786.MCR-17-0332

7. Secrier M, Li X, de Silva N, et al. Mutational signatures in esophageal adenocarcinoma define etiologically distinct subgroups with therapeutic relevance. Nat Genet. 2016;48(10):1131-1141. doi:10.1038/ng.3659

8. Frankell AM, Jammula S, Li X, et al. The landscape of selection in 551 esophageal adenocarcinomas defines genomic biomarkers for the clinic. Nat Genet. 2019;51(3):506-516. doi:10.1038/s41588-0180331-5

9. Labots M, van der Mijn JC, Beekhof R, et al. Phosphotyrosine-basedphosphoproteomics scaled-down to biopsy level for analysis of individual tumor biology and treatment selection. J Proteomics. 2017;162:99-107. doi:10.1016/j.jprot.2017.04.014

10. Lim YP. Mining the tumor phosphoproteome for cancer markers. Clin Cancer Res. 2005;11(9):3163-3169. doi:10.1158/1078-0432. CCR-04-2243

11. Carter AM, Tan C, Pozo K, et al. Phosphoprotein-based biomarkers as predictors for cancer therapy. Proc Natl Acad Sci U S A. 2020;117 (31):18401-18411. doi:10.1073/pnas.2010103117

12. Du Z, Lovly CM. Mechanisms of receptor tyrosine kinase activation in cancer. Mol Cancer. 2018;17(1):58. doi:10.1186/s12943-018-0782-4

13. Drake JM, Graham NA, Stoyanova T, et al. Oncogene-specific activation of tyrosine kinase networks during prostate cancer progression. Proc Natl Acad Sci U S A. 2012;109(5):1643-1648. doi:10.1073/pnas.1120985109

14. Andrechek ER, Muller WJ. Tyrosine kinase signalling in breast cancer: tyrosine kinase-mediated signal transduction in transgenic mouse models of human breast cancer. Breast Cancer Res. 2000;2 (3):211-216. doi:10.1186/bcr56

15. Silva JM, McMahon M. The fastest Western in town: a contemporary twist on the classic Western blot analysis. J Vis Exp. 2014;(84) e51149. doi:10.3791/51149

16. Euhus DM, Hudd C, LaRegina MC, Johnson FE. Tumor measurement in the nude mouse. J Surg Oncol. 1986;31(4):229-234. doi: $10.1002 /$ jso. 2930310402

17. Tomayko MM, Reynolds CP. Determination of subcutaneous tumor size in athymic (nude) mice. Cancer Chemother Pharmacol. 1989;24 (3):148-154. doi:10.1007/BF00300234

18. Li YT, Qian XJ, Yu Y, et al. EGFR tyrosine kinase inhibitors promote pro-caspase-8 dimerization that sensitizes cancer cells to DNA-damaging therapy. Oncotarget. 2015;6(19):17491-17500. doi:10.18632/oncotarget.3959

19. Eskens FA, Mom CH, Planting AS, et al. A Phase I dose escalation study of BIBW 2992, an irreversible dual inhibitor of epidermal growth factor receptor 1 (EGFR) and 2 (HER2) tyrosine kinase in a 2-week on, 2-week off schedule in patients with advanced solid tumours. Br J Cancer. 2008;98(1):80-85. doi:10.1038/sj.bjc.6604108

20. Li D, Ambrogio L, Shimamura T, et al. BIBW2992, an irreversible EGFR/HER2 inhibitor highly effective in preclinical lung cancer models. Oncogene. 2008;27(34):4702-4711. doi:10.1038/ onc.2008.109

21. Kim H, Gillis LC, Jarvis JD, et al. Tyrosine kinase chromosomal translocations mediate distinct and overlapping gene regulation events. BMC Cancer. 2011;11(1):528. doi:10.1186/1471-2407-11-528

22. Costa R, Carneiro BA, Taxter T, et al. FGFR3-TACC3 fusion in solid tumors: mini review. Oncotarget. 2016;7(34):55924-55938. doi:10.18632/oncotarget.10482
23. Smith KM, Yacobi R, Van Etten RA. Autoinhibition of Bcr-Abl through its SH3 domain. Mol Cell. 2003;12(1):27-37. doi:10.1016/ s1097-2765(03)00274-0

24. Hochhaus A, Larson RA, Guilhot F, et al. Long-term outcomes of imatinib treatment for chronic myeloid leukemia. $N$ Engl J Med. 2017;376(10):917-927. doi:10.1056/NEJMoa1609324

25. Pao W, Miller VA. Epidermal growth factor receptor mutations, small-molecule kinase inhibitors, and non-small-cell lung cancer: current knowledge and future directions. J Clin Oncol. 2005;23 (11):2556-2568. doi:10.1200/JCO.2005.07.799

26. Jackman DM, Yeap BY, Sequist LV, et al. Exon 19 deletion mutations of epidermal growth factor receptor are associated with prolonged survival in non-small cell lung cancer patients treated with gefitinib or erlotinib. Clin Cancer Res. 2006;12(13):3908-3914. doi:10.1158/ 1078-0432.CCR-06-0462

27. How J, Mann J, Laczniak AN, Baggstrom MQ. Pulsatile erlotinib in EGFR-positive non-small-cell lung cancer patients with leptomeningeal and brain metastases: review of the literature. Clin Lung Cancer. 2017;18(4):354-363. doi:10.1016/j.cllc.2017.01.013

28. Noronha V, Patil VM, Joshi A, et al. Gefitinib versus gefitinib plus pemetrexed and carboplatin chemotherapy in EGFR-mutated lung cancer. J Clin Oncol. 2020;38(2):124-136. doi:10.1200/JCO.19.01154

29. Park K, Tan EH, O’Byrne K, et al. Afatinib versus gefitinib as first-line treatment of patients with EGFR mutation-positive non-small-cell lung cancer (LUX-lung 7): a phase 2B, open-label, randomised controlled trial. Lancet Oncol. 2016;17(5):577-589. doi:10.1016/S1470-2045(16)30033-X

30. Sun Z, Shi Y, Shen Y, Cao L, Zhang W, Guan X. Analysis of different HER-2 mutations in breast cancer progression and drug resistance. J Cell Mol Med. 2015;19(12):2691-2701. doi:10.1111/jcmm. 12662

31. Ross JS, Fletcher JA. HER-2/neu (c-erb-B2) gene and protein in breast cancer. Am J Clin Pathol. 1999;112(1Suppl 1):S53-S67.

32. Chakravarty D, Pedraza AM, Cotari J, et al. EGFR and PDGFRA co-expression and heterodimerization in glioblastoma tumor sphere lines. Sci Rep. 2017;7(1):9043. doi:10.1038/s41598-017-08940-9

33. Fleming TP, Saxena A, Clark WC, et al. Amplification and/or overexpression of platelet-derived growth factor receptors and epidermal growth factor receptor in human glial tumors. Cancer Res. 1992;52 (16):4550-4553.

34. Sun T, Aceto N, Meerbrey KL, et al. Activation of multiple proto-oncogenic tyrosine kinases in breast cancer via loss of the PTPN12 phosphatase. Cell. 2011;144(5):703-718. doi:10.1016/j. cell.2011.02.003

35. Diamantopoulou Z, Kitsou P, Menashi S, Courty J, Katsoris P. Loss of receptor protein tyrosine phosphatase $\beta / \zeta(\mathrm{RPTP} \beta / \zeta)$ promotes prostate cancer metastasis. J Biol Chem. 2012;287 (48):40339-40349. doi:10.1074/jbc.M112.405852

36. Wang X, Goldstein D, Crowe PJ, Yang JL. Next-generation EGFR/ HER tyrosine kinase inhibitors for the treatment of patients with non-small-cell lung cancer harboring EGFR mutations: a review of the evidence. Onco Targets Ther. 2016;9:5461-5473. doi:10.2147/ OTT.S94745

37 Landi L, Tiseo M, Chiari R, et al. Activity of the EGFR-HER2 dual inhibitor afatinib in EGFR-mutant lung cancer patients with acquired resistance to reversible EGFR tyrosine kinase inhibitors. Clin Lung Cancer. 2014;15(6):411-417.e4. doi:10.1016/j.cllc.2014.07.002

38. Rush J, Moritz A, Lee KA, et al. Immunoaffinity profiling of tyrosine phosphorylation in cancer cells. Nat Biotechnol. 2005;23(1):94-101. doi:10.1038/nbt1046

39. Li H, Ren Z, Kang X, et al. Identification of tyrosine-phosphorylated proteins associated with metastasis and functional analysis of FER in human hepatocellular carcinoma cells. BMC Cancer. 2009;9:366. doi:10.1186/1471-2407-9-366

40. Howlader N, Forjaz G, Mooradian MJ, et al. The effect of advances in lung-cancer treatment on population mortality. $N$ Engl J Med. 2020;383(7):640-649. doi:10.1056/NEJMoa1916623 
41. Wei Y, Zou Z, Becker N, et al. EGFR-mediated Beclin 1 phosphorylation in autophagy suppression, tumor progression, and tumor chemoresistance. Cell. 2013;154(6):1269-1284. doi:10.1016/j. cell.2013.08.015

42. D’Errico G, Alonso-Nocelo M, Vallespinos M, et al. Tumorassociated macrophage-secreted $14-3-3 \zeta$ signals via AXL to promote pancreatic cancer chemoresistance. Oncogene. 2019;38 (27):5469-5485. doi:10.1038/s41388-019-0803-9

43. Girnun GD, Chen L, Silvaggi J, et al. Regression of drug-resistant lung cancer by the combination of rosiglitazone and carboplatin. Clin Cancer Res. 2008;14(20):6478-6486. doi:10.1158/1078-0432.CCR08-1128
44. Sun T, Yang Q. Chemoresistance-associated alternative splicing signatures in serous ovarian cancer. Oncol Lett. 2020;20(1):420-430. doi:10.3892/ol.2020.11562

45. Thomson S, Petti F, Sujka-Kwok I, Epstein D, Haley JD. Kinase switching in mesenchymal-like non-small cell lung cancer lines contributes to EGFR inhibitor resistance through pathway redundancy. Clin Exp Metastasis. 2008;25(8):843-854. doi:10.1007/s10585-0089200-4

46. Brown R, Curry E, Magnani L, Wilhelm-Benartzi CS, Borley J. Poised epigenetic states and acquired drug resistance in cancer. Nat Rev Cancer. 2014;14(11):747-753. doi:10.1038/nrc3819

\section{Publish your work in this journal}

OncoTargets and Therapy is an international, peer-reviewed, open access journal focusing on the pathological basis of all cancers, potential targets for therapy and treatment protocols employed to improve the management of cancer patients. The journal also focuses on the impact of management programs and new therapeutic

Submit your manuscript here: https://www.dovepress.com/oncotargets-and-therapy-journal agents and protocols on patient perspectives such as quality of life, adherence and satisfaction. The manuscript management system is completely online and includes a very quick and fair peer-review system, which is all easy to use. Visit http://www.dovepress.com/ testimonials.php to read real quotes from published authors. 